\title{
The Unstoppable Rise of Mobile Imaging and Aesthetics
}

\author{
Murat Germen \\ Sabanci University, FASS \\ Orhanli, Tuzla, 34956, \\ Istanbul, Turkey \\ muratgermen@sabanciuniv.edu
}

\begin{abstract}
Smart phones are ubiquitous; light, portable and indispensable. The spatial, perceptive and visual connections among scene, subject and photographer are different, compared to a regular camera. This fact enables the photographer to focus on different topics, try practices s/he has not tried before. Mobile devices change the way we create, edit, sequence and share photography. When you do street photography with a smart phone camera, one of the advantages is that people do not really understand where you aim at and what you photograph. They do not react as consciously as they would in front of a regular camera. The reason is; almost all people, including locals and tourists, own a smart phone and taking a snap with them is very common practice for all. Okabe and Ito (2006) argue that: "The camera phone is a more ubiquitous presence, and is used for more personal, less objectified viewpoint and sharing among intimates. It tends to be used more frequently as a kind of archive of a personal trajectory or viewpoint on the world, a collection of fragments of everyday life."
\end{abstract}

Ease of use seems to make smart phone recording as one of the "sine qua non" practices of photography. There are many documentary photographers, reporters, journalists, professional photographers and even artists, film directors who take this apparatus seriously and use it. Some camera makers, like Samsung, are aware of the power of mobile imaging (described as "quantum imagery" by Fred Ritchin) and started to produce cameras 3G/4G connectivity.

Before the digital revolution, the percentage of the "amateur" photographers was relatively less as compared to the digital era. Shooting with film was more difficult as analogue processes allowed less room for errors. After the launch of cheap compact digital cameras amateurs generated more self-confidence in imaging since they were offered the possibility of fixing any mistakes by just erasing any faulty photo. The introduction of cameras into smart phones was yet another dimension at which people felt even more poised to take photos, since the tool is not a "professional" apparatus with which you are expected to create expert results. In the light of above facts, I think it would not be wrong to say that phone cameras give a personalized power to their users. Nowadays, with the possibilities offered by social media tools, regular people contribute to the making of their local and global histories with the "amateur" personal images they make, which partially shape their identities. This can defined as power of the individual, using visual imagination as a tool.

This paper aims to discuss how mobile digital imaging alters the creation, perception and aesthetics of visuality. Contemporary photographic culture is definitely more intricately intertwined with popular culture as compared to photography in the 20th century and this should not be interpreted as a weakness but strength, when used consciously.

Mobile imaging. Individuality. Digital aesthetics. Visual communication. Contemporary photography.

\section{INTRODUCTION}

Communication through visuals is not novel practice. It is rather the most archaic way of conveying information, considering the Palaeolithic drawings of the Lascaux Cave. Following the evolution of primitive image making into figurative painting, analogue photography using camera obscura and its technological derivatives into digital image making; it seems we are going back to the very first days of humankind where images did not need textual explanation. Another contemporary tool that proves there are no language and communication barriers with images is the "Point it Traveller's Language Kit" where you have only photos to explain your need by pointing to images. 
"This is a time where we are moving away from photography as a way of recording/storing a past moment. We are turning photography into a communication medium. You have images now that have no possible afterlife, said Robin Kelsey, a professor of photography at Harvard. As a form of brisk visual response, Snapchat is a mobile application that allows a person to take and send a picture or video, then control how long (10 seconds max) it's visible to the person who receives it. After the photo is viewed, it disappears forever, like a casual exchange on the street." (Bilton 2013).

The aforesaid ephemerality of mobile visual communication turns mobile devices into vital media tools. Here are some facts that prove the prevalence of smartphones and instant image making:

(i) Social media giant Facebook has offered \$1 billion for Instagram, instant image sharing platform.

(ii) In 2011, Park Chan-wook (South Korean film director) shot his new film titled "Paranmanjang" entirely on the iPhone 4. http://en.wikipedia.org/wiki/Night Fishing (fi Im)

(iii) Stock photo agencies entered mobile photography market. Many major stock photo agencies started to deploy images taken with smartphones and commission photographers using them.

(iv) 4 of the 5 "Most Popular Cameras in the Flickr Community" list are iPhones by the time this paper was written (iPhone $5,4 \mathrm{~s}$, 5s, 4 respectively, leading Canon EOS Rebel T3i). The same list in November 2012 went as follows: iPhone 4s, Canon EOS 5D Mark II, iPhone 4, Canon EOS EOS 7D, Canon EOS Rebel T2i. http://www.flickr.com/cameras

(v) An infographic by Overgram, display interesting titbits: Facebook has 10,000 times more photos than the Library of Congress, photos make up $42 \%$ of posts on Tumblr.http://mashable.com/2012/11/17/ph otography/

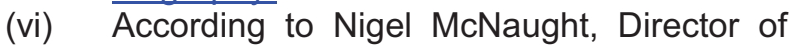
the Photo Marketing Assoc., "it's realistic to assume some of the loss in compact camera unit sales is down to smartphones." http://www.dpreview.com/articles/98901461 01/how-smartphones-are-changing-digitalphotography

(vii) Smartphones are occasionally preferred for news reporting / TIME-Superstorm Sandy (http://www.americanphotomag.com/photogallery/2013/03/iphoneonly) Al Jazeera Coverage of the uprising in Syria (http://mashable.com/2012/04/02/syriaiphone-documentary/) New York Times -
US Army's presence in Afghanistan (http://lens.blogs.nytimes.com/2011/02/11/t hrough-my-eye-not-hipstamatics/)

(viii) Fortune magazine reported in September 2012 , that " $10 \%$ of all photos ever taken were shot in 2011." http://www.wired.com/rawfile/2012/11/steph en-mayes-vii-photography/

(ix) Release of smartphones with very high resolution cameras (41-megapixel Nokia Lumia 1020), prosthetic lenses that can be attached onto smartphones to augment optical features (20-megapixel Sony DSCQX100 Digital Camera Module for Smartphones) show that companies invest on smartphone imaging and will continue to do so in the future.

(x) One of Google's latest technologies, Google Glass, is a wearable computer with an optical head-mounted display and brings an extra facet to mobile imaging.

(xi) "Comparative international statistics convey the magnitude and speed of these changes and the growth of the mobile phone; people worldwide are more likely to own a telephone than the more celebrated 'miracle' of communication technology, the TV." (Katz \& Aakhus 2002).

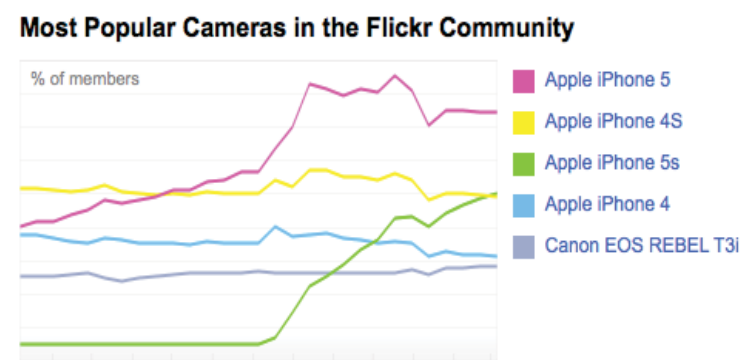

Figure 1: Most popular cameras in the Flickr community: iPhone 5, 4s, 5s, 4 respectively, leading Canon EOS Rebel T3i

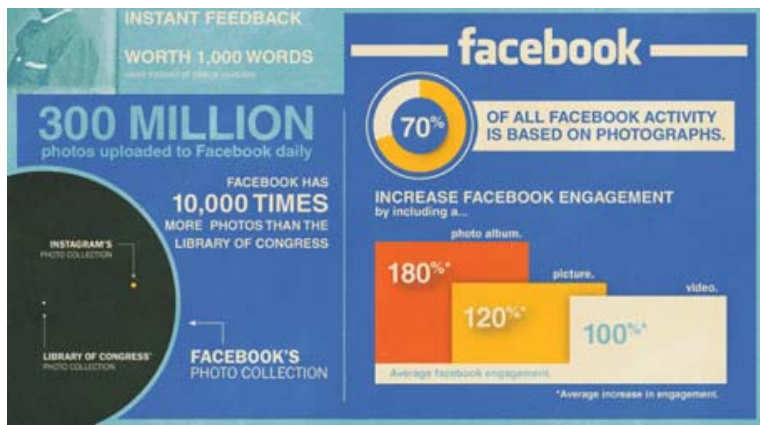

Figure 2: Facebook has 10,000 times more photos than the Library of Congress (infographic by Overgram)

The dominance of mobile imaging devices can further be explained by the following quote: "Images' meanings morph, move and can exist in multiple places and meanings at one time. Fred 
Ritchin, professor of photography and imaging at NYU describes this as 'Quantum imagery.' Digital photography is anything and everything at any single moment; it has contradictory meanings all at once. What the cell phone does is it takes all the attributes of digital and magnifies them." (http://www.wired.com/rawfile/2012/11/stephenmayes-vii-photography/)

\section{ADVANTAGES OF SMARTPHONES AS MOBILE IMAGING DEVICES}

The first benefit is very obvious: ubiquitousness. We already need the device for basic communication. It is small, lightweight, fits almost any pocket. It creates the feeling of "unbearable lightness" by getting rid of the physical and mental weight of having to carry pro-camera paraphernalia. The next big advantage is connectivity. This is so crucial that Samsung produced a new camera titled Galaxy Camera 3G $\& \mathrm{Wi}-\mathrm{Fi}$, which provides immediate Internet access for sharing photos on social media.

'Instant eyewitness' is another chief dimension; an instant photo is an instant evidence: You can use it to document a car accident to prepare your claim for the insurance company, you can prove you were at a certain location at a certain time to answer questions of "where were you last ...?", you can start documenting the drastic physical changes in your neighbourhood (e.g. the author's "urban transformation" series in progress in his home town of Istanbul) and you can also join social / political movements by providing testimonial images that are not covered by main stream media. Among some recent examples to this enlightening type of image making are the cell phone photos taken by Iraqi civilians that allege indiscriminate use of violence against civilians and children by military forces of the USA in the city of Fallujah in Iraq during the Fallujah Offensive of November 2004. The photos taken by "amateurs" during the Tahrir Square (Cairo, Egypt) and Taksim Gezi Park resistance / demonstrations (Istanbul, Turkey) and shared in social media aiming a transparent communication, were very strong human rights violation evidences of state aggression towards protesting civilians, that were not covered by mass media frightened by state institutions.

The smartphone for a pro-photographer is an ideal tool. The device is used by almost everybody, taking a snap with it is very common practice and it does not have a "pro" look. So the prophotographer is part of the clan, nobody takes her/him seriously and poses accordingly, just like the children photographers are usually treated. In case of smartphone photography, people do not react as consciously as they would in front of a regular camera. This is perfect in the sense that "candid" photos are expected in typical street photography. The other advantage is that people do not really understand where you aim at and what you exactly photograph. On the other hand, when you work with models aware of you photographing with a smartphone, subjects feel more comfortable and therefore allow the persona to come out more, since they can stare at the photographer's face instead of the lens+camera set. Furthermore, typical camera viewfinder vision and distantly held smartphone vision are not the same; you have a larger scope of view with smartphones, since you do not feel confined to the viewfinder's tunnel-like vision.

A pro-photographer must change his/her imaging device periodically in order to be able to behave differently towards the subject/object. Depending on the particular project she/he is working on, experimenting with different equipment like analogue camera with film, D-SLR, GoPro camera, GigaPan Epic Pro, Lomo, smartphone with apps, etc. will add a serendipitous dimension, adventitious mode of creativity that was not previously tested.

\section{POSSIBLE DRAWBACKS OF WORKING WITH MOBILE CAMERAS}

Photography reveals things that are otherwise not visible to us at that very moment. If the content to be revealed is confidential or private, the issues of ethics have to be considered. The more omnipresent is the smartphone camera, the more there is potential to violate the privacy of individuals and conveying misinformation by documenting moments that are isolated from their contexts. "The Society of Professional Journalists mandates the following in its Code of Ethics: Never distort the content of news photos or video. Avoid misleading re-enactments or staged new events. If reenactment is necessary to tell a story, label it. Ethics refers to a discipline, theory, or other system that seeks to provide moral guidelines by integrating or balancing personal values with institutional or community obligations." (Wheeler 2002). Various countries apply different sanctions in cases of privacy violation, violation of copyright for photographing design objects to be replicated without permission, lack of signed model release from the subject who was photographed and similar content problems. These different procedures taken against various cases are usually shared on the Internet in order to form a pool of possible legal actions that individuals, institutions can refer to. Aside from the collective legal dimensions, the subject of ethics has first to do with personal conducts and discipline. The basic motto is easy as 'respect others if you want to be respected.' 
The ease of creating a photo instantly carries the potential of leading people to photograph just anything and share carelessly without much elimination, screening. Once photographers become famous (almost like World of Warcraft avatars) in platforms like Instagram and their ten thousands of followers keep liking any photo they share, there is the danger of experiencing a quality loss both in content and aesthetics. This is like almost like Narcissus syndrome, which is a character that fell in love to death with his reflection on a pool, not realizing it was merely an image. We easily fall in love with our own social media presence, not realizing the fact that most of the images that we create carry the signature of the retro filters that we happen to choose; when we share images from platforms like Instagram, Hipstamatic, EyeEm, VSCO Cam and so on. Some of these digital enhancements are quite easy to identify and your image may be first be labelled by app names before your name.

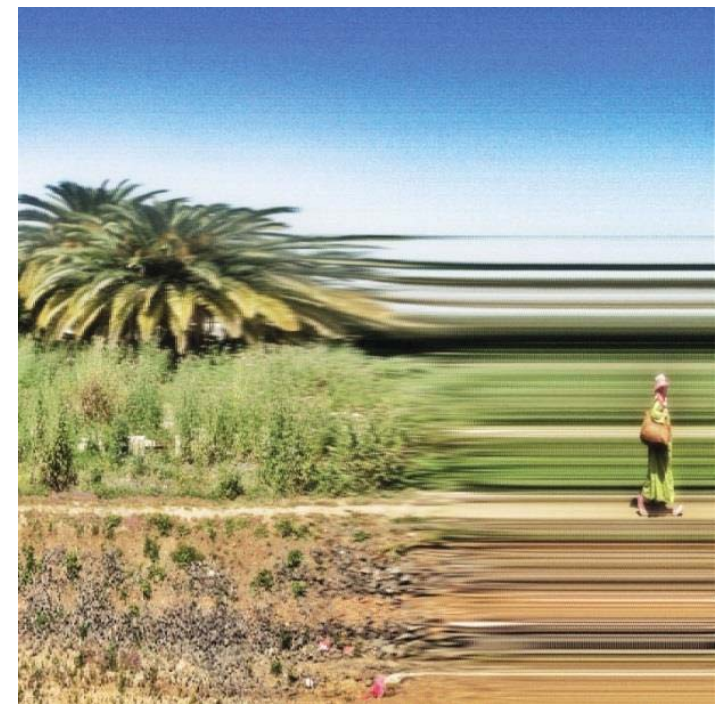

Figure 3: Image obtained with the combination of iPhone 5 + Slitscan app on iOS. Copyright: Murat Germen, 2013

Smartphones are technological wonders and people who do not conceive them just as tools but rather as prestige items will miss the train. Technofetishistic idolatry or technological triumphalism under the form of iPhone/Samsung or iOS/Android fanaticism will serve dominant technoculture that discusses tech features, instead of discussing how you can contribute to your culture and politics.

\section{SOCIOLOGICAL DIMENSIONS OF MOBILE IMAGE MAKING}

For a moment, forget digital technologies and remember the old travel / family photos that existed at home, either framed and located on a buffet in a living room or on the pages of an album to be shared periodically with others. These photos were displayed publicly and meant to be seen by others. Yet, this public group of folks was composed of relatives and friends, or friends of friends at the outermost range. These photos referred to the past, recent or remote, and they were visual proofs of I was (we were) there / like this / with others at a particular time. This structure changed quite a bit with instant photography and sharing. Now, we have a much larger group of people we get connected to (much more than we can host of home) and we are more interested in what we are doing now, as opposed to what we have done in the past. So, the famous "Kilroy was here" graffiti may need to be modified as "Kilroy is here right at this time, don't miss!" This simultaneity matters so much for some people that if you are not doing anything at this time you may not be even considered alive.

The use of smartphones, including the simpler models only with SMS, MMS capabilities, is quite widespread among the youth. "The popularity of mobile photography among young people is rooted in the intrinsically identificational and relational practices and rituals of mobile snapshots. The focus is the social networks of belonging more often than the subject. Both online communication and mobile photography are performative practices, connected to the representation and narration of daily life, and often oriented towards the building and preservation of memory. Yet, at the same time, they are used to exhibit one's social memberships and aimed at maintaining reciprocal connectivity. In a sense, the circulation of mobile pictures in Web 2.0 environments shows that mobile images are a socio- cultural phenomena." (Scifo 2009) "For teens, three processes are formative in constructing their identities: reflexivity, makeability and individualization." (Ziehe 1989).

Exhibitionistic over-presence in the social media platforms using 'selfie's and socialisation photos may point to the efforts of short-lived media publicity / celebrity and remind the expression credited to Andy Warhol that goes as follows: "In the future, everyone will be world-famous for 15 minutes." This trend, in addition to other social media tendencies, is not specific to cultures: "Mobile communication changes the nature and quality of social behaviour and organisation. These changes are not restricted to the industrialized countries, but are pandemic." (Katz \& Aakhus 2002). The most probable reason is the fact that "photos reflect social relationships but they also help to construct and maintain them." (Van House et al. 2004).

Use of smartphones is also closely linked with how we use public space. When Turkish people started to use cell phones publicly, before the 'mobile 
communication etiquette' was widely adopted by the culture, there were problems of public disturbance due to high voice volume or cultural variations in the definition of which speech content is public or private. "Mobile phone use appears to encourage the privatisation of public space, as private discourse fills the street, classroom and every other conceivable public space. In so doing, speakers 'absent' themselves from the spaces they inhabit. Mobile technologies permit a reorganisation of public and private realms of experience where what is traditionally conceived of as 'private' experience is brought out into public realms in the act of individualized listening or talking. These technologies permit users to prioritize their experience in relation to their geographical, social and interpersonal environment, enabling them to exist, in a variety of ways, within their own private sound-world." (Bull 2004).

Smart phones are not initially meant as imaging devices and there are some social issues involved in using them as communication devices. Various cultures generated different reactions and habits:

(i) "The mobile as a personal communication device, not jointly used by the family like the traditional fixed-line phone." (Kasesniemi \& Rautiainen 2002).

(ii) "The SMS phenomenon that has generated its own terminology, customs and social norms" (Kasesniemi \& Rautiainen 2002).

(iii) "SMS as clique-based abbreviated language" (Skog 2002).

(iv) "The significance of social background decreasing while the subjective importance of the inner world increasing as industrial society develops" (Skog 2002).

(v) "Mobile phone as a status symbol among working class teenagers" (Skog 2002).

(vi) "Mobile phone as a tool of uneducated people to show off new social status" (Varbanov 2002).

(vii) "Usage of mobile phone in the house as a substitute for a cordless phone" (Fortunati 2002).

The above are several early conventions that were adopted in countries like Finland, Norway, Bulgaria, and Italy.

\section{EFFECTS OF MOBILE IMAGING ON CONTEMPORARY PHOTOGRAPHY, VISUAL AESTHETICS AND CONTENT CREATION}

Though smartphone cameras are technically decent to an acceptable degree, they cannot reach the quality of professional cameras. Some of them are low in MP value, all of them have weak hi-ISO performance, almost none offer optical zoom capability and these facts prevent these devices from being used in most professional photography cases. As a result of these technical shortcomings, most images created by smartphones are defective in the sense of having noise, light leaks, awkward compositions due to fast usage routine, etc. This fact is highly compatible with the present day photography aesthetics of imperfections and dilapidations. Following the many-decades-old normative approach of excessive concentration on aesthetics, technical perfection in photography; some contemporary photographers preferred to focus on imperfections as a refusal of overaestheticized imagery. In some cases of such practice, imperfection referred to the genuineness of the testimony; where in others, it was purely a quest for novel aesthetics defying the traditional.

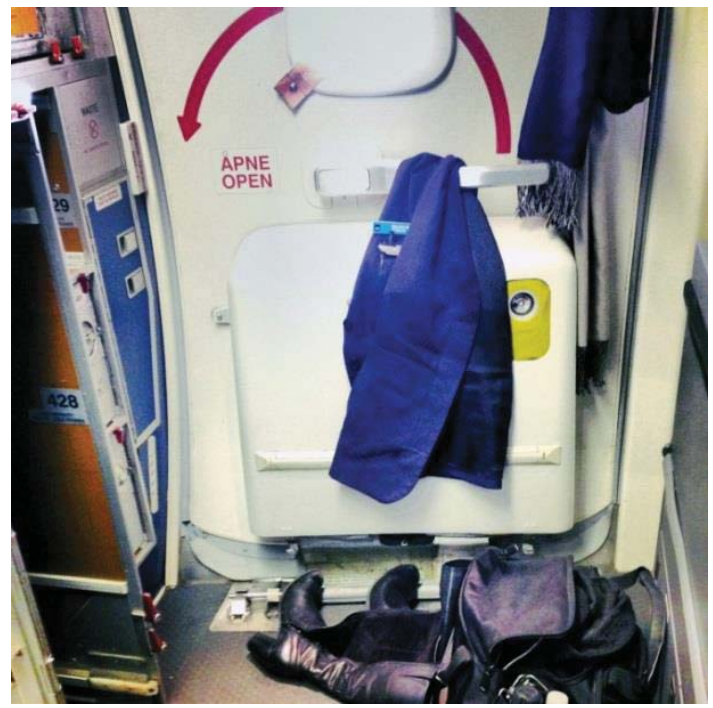

Figure 4: Instagram photo: Murat Germen, inside an airplane, 2014

Bernd Stiegler states in his article (dated 2012 and titled 'Imperfection' published online at the Fotomuseum Winterthur site) "that imperfection serves as the contemporary modus of the real in photography. For this very reason photography has become enamoured of and committed to inaccuracy, because it enables a form of representation that aims to conceptualize reality in a unique aesthetic manner."

(http://blog.fotomuseum.ch/2012/01/1imperfection/).

Obtaining imperfection in photography can happen at numerous levels: First method refuses the perfection of technology by making photographs that deliberately utilize pre-planned technical errors. These erroneous processes can be listed as follows: Deficient cameras, expired / partially exposed / torn films, various chemical tweakings in the darkroom, etc. Any content photographed with such flawed equipment is doomed to yield an imperfect result, even if you document perfection. Second method is at the user level: Photographer exploits user controlled inaccuracies like blurriness, 
"bad" framing, overexposure, underexposure, accidental shutter moves, etc. If this is combined with the first method, rare results due to accidental idiosyncrasy are guaranteed. As an artist trying to be as "eccentric" as possible, one can easily sympathize with these methods; since complying with rules and technical requirements offers you less opportunity in creating something unique. Another method is closely related to the core function of photography, which is documentation. Documenting the imperfections in life in a very straight manner, avoiding above-mentioned methods resting on technical flaws, enables photographers to refer to the new aesthetic of faultiness. The recent occurrence of photographic imperfection in mobile imaging environments partially seems to be nostalgic, as many filters that are used in smartphone photo apps simulate the aforementioned technical imperfections. This also means that the original "anti-aesthetic" approach aiming imperfection has become a dominant aesthetic itself, just like Duchamp's appropriation of ready-mades lost its revolutionary meaning.

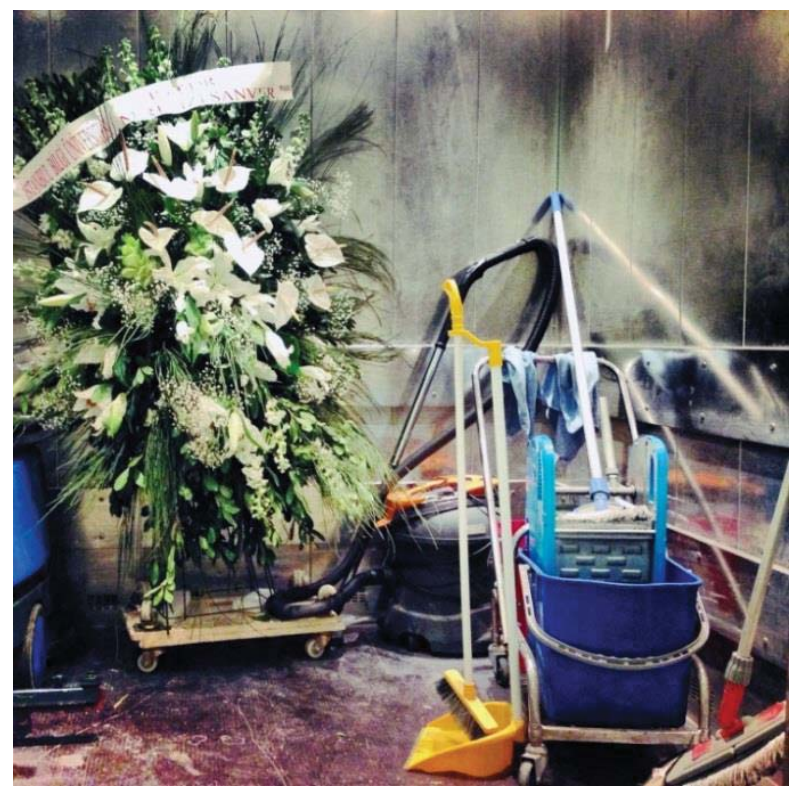

Figure 5: Instagram photo: Murat Germen, Istanbul, Turkey, 2014

If one tries to connect the habit of using smartphones to contemporary photography practices, it is possible to talk about an overlap of both practices in covering personal narratives. Following Nan Goldin's personal story making of one's own surroundings, many relatively new generation photographers chose / still choose to work on 'close quarters.' "People capture ordinary things in immediate life and share them with friends and acquaintances in monadic clusters that become even more emotionally and relationally more self-reliant than before." (Koskinen 2005) "Stephen Mayes, director of VII Photo Agency, argues that the rise of digital changed the very nature of photography by moving it from a fixed image to a fluid one. Our new relationship is less about witness, evidence and document and much more about experience, sharing, moment and streaming. The cell phone is a harbinger for something hugely significant. Given the centrality of personal photography to processes of identity formation and memorialisation, changes to the ways in which we capture, store, and disseminate personal photographs through the use of devices like camera phones will have important repercussions for how we understand who we are and how we remember the past." (Gye 2007).

The democratisation of image making brought by mobile devices and resulting increase in the introduction of personal narratives forming a collective pool of experiences can be exemplified with the recent social movements like the Arab Spring or the Taksim Gezi Park resistance in Turkey. "Research has demonstrated information sharing via mobile phones as being a significant means for decision making in informal groups." (Miranda \& Saunders 2003) The plurality of different, or even opposing informal individualities is central to the concept of a developed culture. The pool of images created by "amateurs" carries the potential of being truer in the sense that they are neither photos required, commissioned by hegemonic press agencies (Reuters, AFP, etc.) nor taken by professional photographers who are very experienced in creating photos as instruments to be exploited by prevailing nations. In other words, there is an increasing autonomy of the making of images (pictures) and decreasing significance of photos of commissioned by official / private institutions to clean their images (appearance). Visual appropriation, manipulation and control of the world are not in the hands of exclusive people / institutions anymore. The way photography constructed the world visually changed: "the certainties of the photographic era have been deconstructed, and we are now ready, it seems, to come to terms with the fragility of ontological distinctions between imaginary and real." (Robins 1996).

I remember the old days when I was working with positive film. My budget was limited as a young photographer; on the other side, slide film was highly unsparing and it would not forgive any mistakes. Therefore, bracketing was inevitable and every time I bracketed I would be concerned about the final expenses. One film frame had a particular value as an "object" of obsession, both physically and mentally. This is not the case anymore with digitally taken frames. All the photos you take are "free" of cost, time, concern, hesitation; you take them continuously in a succession you never intended before. This carelessness frees you from the physical attachment you feel towards a single 
frame; yes we produce quickly, yes we consume quickly but also create extra expressions about situations we are impressed by. What we individually create nowadays is not a representational proof that will serve the official history dictated to us for long years, it is rather our humble personal observation that has a destiny of its own in terms of sustainability. The image no longer serves to signify the object; but, rather, suggests it, uncovers it, makes it subsist. As Gene Youngblood puts it: "a digitally processed photograph, for example, can no longer be regarded as evidence of anything external to itself. Digital scene simulation has deprived photography of its representational authority just as photography disqualified painting in the nineteenth century; but this time the question of representation has been transcended altogether." (Youngblood 1989).

The omnipresence of smartphones as imaging devices has a strong impact on the fact that they encourage, help us to take photos in places, instances, settings, occasions we would not otherwise think of photographing. Following a humble personal observation, I think we started to see more aerial photos from airplanes, more animal / food / action photos, more self-portraits, more photos from TV screens, and so forth. The angle, perspective, viewpoint, framing of this relatively unusual content is also uncommon. A lot of "regular" people, who previously had average approach towards photography, started to experiment; they are not scared of making mistakes, producing strange, bizarre, atypical images in addition to 'normal' ones. More people want to be creative and appreciated; this will hopefully force art professionals and artists to think of an update, which is long needed after the 100th year commemoration of Duchamp's works.

Last dimension I would like to mention is related to two of the most indispensable components of photography: Time and space. Most of the smartphones have built-in GPS modules and consequently photos come tagged with GPS metadata, which allows locating the photo on a map in a precision that was not available before. This geo-location coding coupled with time coding refer to a space information that we can call GIS territory / GIS place / data landscape. In addition to the visual, cultural, aesthetical, artistic, social, anthropological information embedded into them directly or indirectly, photos started to convey location data as well. Aesthetics can be seen as purely visual reading, yet context will always influence the way we perceive and interpret visualities. Talking about landscape as cultural context, one must also keep in mind that "the physical landscape is also changing. Ungainly signal transmission towers are prominent features of one's view of the panoramic landscape." (Katz \& Aakhus 2002).

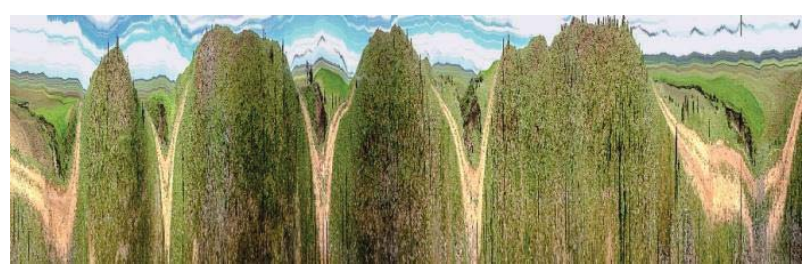

Figure 6: Compressed landscape image taken from a moving train with an iPhone app named Slitscan

(Photograph: Murat Germen, Morocco, 2013)

\section{CONCLUSION}

Investigation of the concepts of place, cognition, conception, making and aesthetics of mobile imaging in photographic and popular cultures is crucial, considering the rapidly changing landscape of today's cyberculture. The escalation of smartphone photography has given control to individuals to have the opportunity to create their own narratives / visual stories and share them with others without hindrance or moderation. This new popular culture illustrated by a dynamic visual assemblage is intertwined with contemporary photographic culture and this link should be seen as a strength when used / perceived consciously. Individuals forming a collective pool of instant personal experiences and representations in cyberspace point to the triumph of subjective casualness over objective formalism. This individual conscience can be further explained with Kevin Robins' statement: "in the light of a felt sense of insecurity, images are mobilised to achieve symbolic or imaginary possession over space: they are about containment and control." (Robins 1996).

The presently much ominous notion of surveillance, violation of personal privacy in the name of security, disturbing presence of the excessive numbers of CCTV cameras constitute important aspects to consider in mobile imaging as individual mode of existence. The fact that almost anybody at any time can photograph anybody else with the help of ubiquitous smartphones can be seen alternatively as an act of subjective resistance tool, reminiscent of small brothers watching the "big brother," against the unconsented visual recording for security excuses. This conception can be taken as a global collective panopticon with many contributors from around the world, which are not "prisoners" of technology but hopefully conscious individuals who are not blinded by the "Apparatgeist" (spirit of the machine), a term coined by James E. Katz and Mark A. Aakhus. (Katz \& Aakhus 2002). 
Finally, I think we owe to digital photography and the recent mobile imaging devices a big deal, just because they made us start questioning the previously trusted relationship between photography and truth. Image making is not solely in the hands of professional image makers anymore, we are able to create our own little contextual temporal realities and sustain them by ourselves without the dictation and/or manipulations of official institutions.

\section{REFERENCES}

Aakhus, M. A., and Katz, J. E. (2002) Perpetual Contact: Mobile Communication, Private Talk, Public Performance. Cambridge University Press, England.

Bilton, N. (2013) Disruptions: Social Media Images Form a New Language Online. http://bits.blogs.nytimes.com/2013/06/30/disruption s-social-media-images-form-a-new-languageonline/? php=true\& type=blogs \& $r=0$ (retrieved 8 March 2014).

Bull, M. (2004) To each their own bubble - Mobile spaces of sound in the city. In Couldry, N., and McCarthy, A. (eds.), Mediaspace: Place, Scale, and Culture in a Media Age, Routledge, New York.

Fortunati, L., and Manganelli Rattazzi, A. M. (2008) The Social Representation of Telecommunications. Personal and Ubiquitous Computing, Vol. 12, Issue 6, pp. 479-479.

Gye, L. (2007) Picture This: the Impact of Mobile Camera Phones on Personal Photographic Practices. Continuum (Journal of Media \& Cultural Studies), 21:2, pp. 279-288.

Kasesniemi, E.-L., and Rautiainen, P. (2002) Mobile culture of children and teenagers in Finland. In Aakhus, M. A. and Katz, J. E. (eds.), Perpetual Contact: Mobile Communication, Private Talk, Public Performance, Cambridge University Press, England.

Koskinen, I. (2005) Seeing with mobile images: towards perpetual visual contact. In Nyiri, K. (ed.), A Sense of Place: The Global and the Local in Mobile Communication, Passagen Verlag, Vienna.

Mante-Meijer, E. (2002) The Netherlands and the USA compared. In Aakhus, M. A. and Katz, J. E. (eds.), Perpetual Contact: Mobile Communication,
Private Talk, Public Performance, Cambridge University Press, England.

Miranda, S. M., and Saunders, C. S. (2003) The social construction of meaning: an alternative perspective on information sharing. Information Systems Research, 14(1), 87-106.

Okabe, D., and Ito, M. (2006) Everyday contexts of camera phone use: steps toward technosocial ethnographic frameworks. In Höflich, J., and Hartmann, M. (eds.), Mobile Communication in Everyday Life: an Ethnographic View, Frank \& Timme, Berlin.

Robins, K. (1996) Into the Image: Culture and Politics in the Field of Vision. Routledge, New York.

Scifo, B. (2007) The Sociocultural Forms of Mobile Personal Photographs in a Cross-Media Ecology: Reflections Starting from the Young Italian Experience. Knowledge, Technology \& Policy, September 2009, Vol. 22, Issue 3, pp. 185-194.

Skog, B. (2002) Mobiles and the Norwegian teen: identity, gender and class. In Aakhus, M. A. and Katz, J. E. (eds.), Perpetual Contact: Mobile Communication, Private Talk, Public Performance, Cambridge University Press, England.

Van House, N. A., Davis, M., Takhteyev, Y., Ames, M., and Finn, M. (2004) The social uses of personal photography: methods for projecting future imaging applications. University of California, Berkeley, Working Papers, CA, USA.

Varbanov, V. (2002) Bulgaria: mobile phones as post-communist cultural icons. In Aakhus, M. A. and Katz, J. E. (eds.), Perpetual Contact: Mobile Communication, Private Talk, Public Performance, Cambridge University Press, England.

Wheeler, T. (2002) Phototruth or Photofiction? Ethics and Media Imagery in the Digital Age. Lawrence Erlbaum Associates, Mahwah, NJ, USA.

Youngblood, G. (1989) The new renaissance: art, science and the universal machine. In Loveless, R. L. (ed.), The Computer Revolution and the Arts, University of South Florida Press, Tampa, USA.

Ziehe, T. (1989) Ambivalenser og Mangfoldighed. Tekster om: Ungdom, Skole, AEstetik, Kultur. (Ambivalences and Multiplicity. Texts on Youth, School, Aesthetics, Culture). Copenhagen: Politisk Revy. 